\title{
Hypomelanosis of Ito presenting with adult-onset dementia and marked enlarged Virchow-Robin spaces
}

Hipomelanose de Ito apresentando como demência de início no adulto e dilatação acentuada dos espaços de Virchow-Robin

Paulo Victor Sgobbi de Souza, Wladimir Bocca Vieira de Rezende Pinto, Fabrício Grecco Calente, Stênio Burlin, José Luiz Pedroso, Acary Souza Bulle Oliveira, Orlando Graziani Povoas Barsottini

A 52-year-old woman presented with a 10-year-history of memory loss and executive dysfunction. Examination disclosed hypopigmented whorls and linear streaks following the lines of Blaschko in different body segments (Figure 1), typical of Hypomelanosis of Ito (HI). Brain MRI showed marked enlarged Virchow-Robin spaces (Figure 2).

$\mathrm{HI}$ or incontinentia pigmenti achromians (MIM\#300337) represents a heterogeneous group of early-onset sporadic neurocutaneous disorders, resulting from chromosomal mosaicism ${ }^{1}$. Neurological manifestation may include: cognitive impairment, epilepsy, spasticity, cerebellar ataxia and microcephaly ${ }^{2}$. Adult-onset neurological symptoms may occur ${ }^{1}$. MRI abnormalities include: white-matter lesions, multiple cerebral infarcts, hypoplasia of the corpus callosum, and enlarged Virchow-Robin spaces ${ }^{2}$.
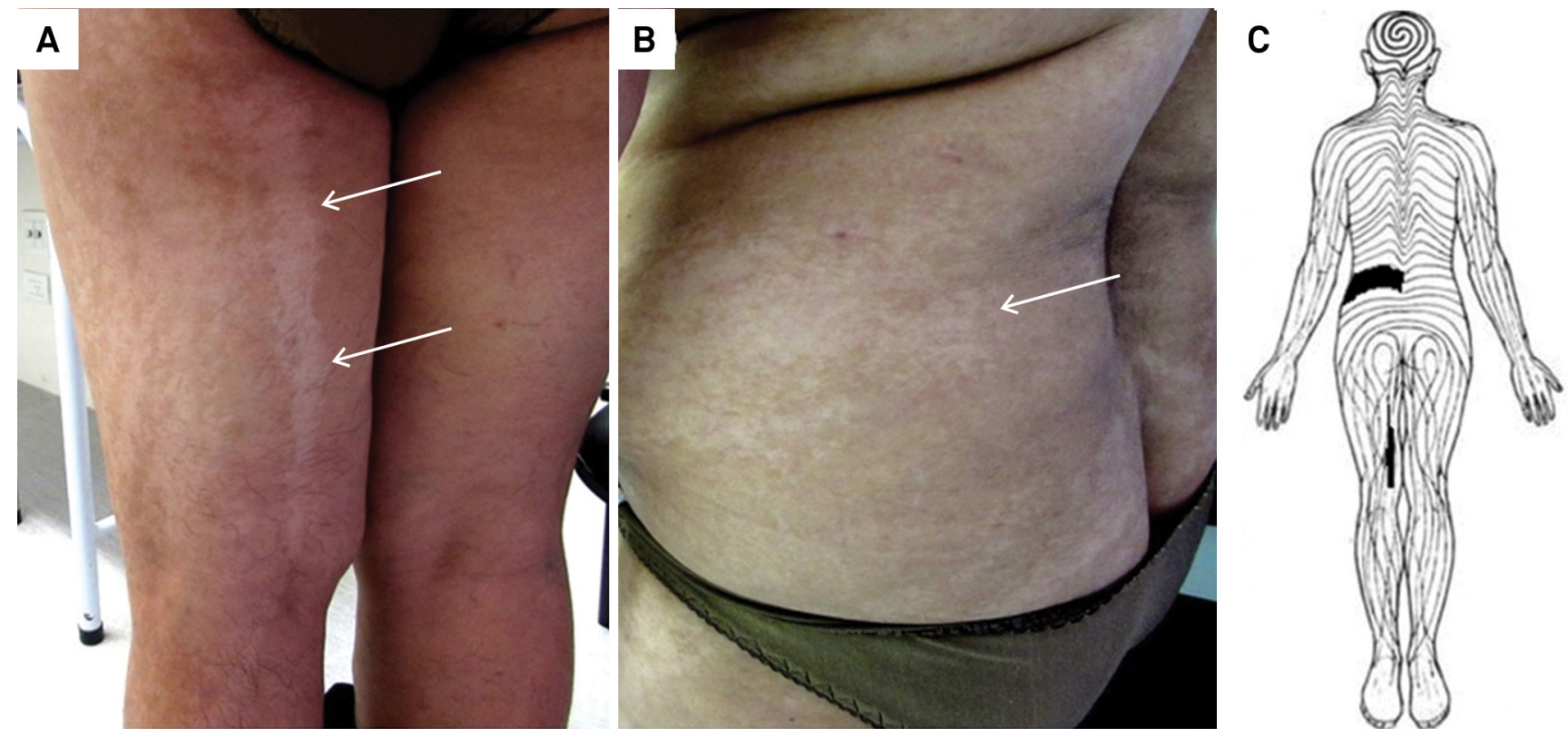

Figure 1. (A and B) Multiple hypopigmented linear streaks following the lines of Blaschko in the posterior surface of the left lower limb and left lumbar region (white arrows). (C) Whole-body representation of the posterior surface disclosing the skin pattern of lines of Blaschko and the most prominent hypopigmented streaks in our patient (filled black areas). 

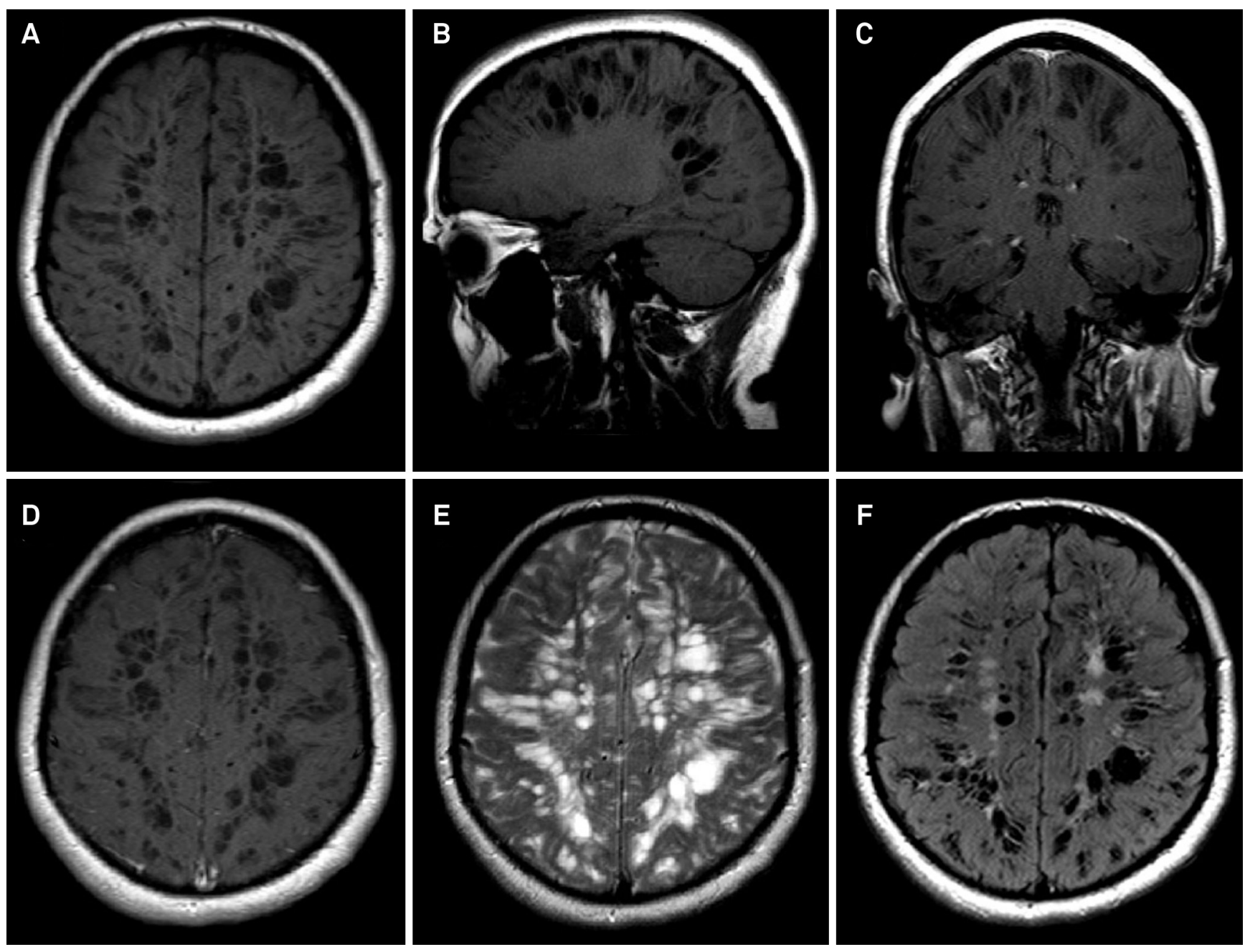

Figure 2. Brain MRI disclosing marked enlarged Virchow-Robin spaces in axial (A) and sagittal (B) unenhanced T1-weighted images and in coronal (C) and axial (D) enhanced T1-weighted images. Axial T2-weighted (E) and FLAIR (F) images shows enlarged Virchow-Robin spaces with mild surrounding gliosis depicted as T2 and FLAIR hyperintense foci.

\section{References}

1. Ruggieri M, Pavone L. Hypomelanosis of Ito: clinical syndrome or just phenotype? J Child Neurol. 2000;15(10):635-44.

http://dx.doi.org/10.1177/088307380001501001
Steiner J, Adamsbaum C, Desguerres I, Lalande G, Raynaud R, Ponsot $\mathrm{G}$ et al. Hypomelanosis of Ito and brain abnormalities: MRI findings and literature review. Pediatr Radiol 1996;26(11):763-8. http://dx.doi.org/10.1007/BF01396196 